\title{
Efficiency of a Tool-mounted Local Exhaust Ventilation System for Controlling Dust Exposure during Metal Grinding Operations
}

\author{
Jun OJIMA ${ }^{1}$ \\ ${ }^{1}$ National Institute of Occupational Safety and Health, 21-1, Nagao 6 chome, Tama-ku, Kawasaki 214-8585, \\ Japan
}

Received January 31, 2007 and accepted June 5, 2007

\begin{abstract}
In general, control of metal dust from hand-held disk grinders is difficult because such respirable dust tends to disperse in every direction around the grinding wheel and cannot be captured effectively by a conventional exhaust hood. The author described the application of a custom-made tool-mounted local exhaust ventilation (LEV) system attached to a hand-held disk grinder, and by laboratory experiments assessed its effectiveness at dust control. The effectiveness of the LEV for dust control was assessed by determining the respirable dust concentration around the grinding wheel during metal surface grinding with and without the use of the LEV. It was shown that the average respirable grinding dust concentration decreased from $7.73 \mathrm{mg} / \mathrm{m}^{3}$ with the LEV off to $4.87 \mathrm{mg} / \mathrm{m}^{3}$ with the $\mathrm{LEV}$ on, a mean dust generation reduction of about $37 \%$.
\end{abstract}

Key words: Ventilation, Dust exposure, Metal grinding

Although the incidence of pneumoconiosis has been decreasing in Japanese industry, inhalation of metal grinding dust remains a serious health hazard. In the 6th Notification of General Prevention of Dust Hazards issued by the Japanese Ministry of Health, Labour and Welfare (2003-2007), metal grinding dust exposure was designated as the principal problem to be resolved. Generally, control of dispersion of metal grinding dust by engineering strategies, especially of dust generated by hand-held disk grinders, is technically difficult because such respirable dust tends to disperse in every direction around the grinding wheel and cannot be captured effectively by a conventional exterior-type exhaust hood ${ }^{1)}$. Hand-held grinders are used extensively throughout industry, usually without any means of dust control, which could be expected to lead to significant dust exposure. In this study, the author described the application of a custommade tool-mounted local exhaust ventilation (LEV) system attached to a hand-held disk grinder, and by laboratory experiments assessed its effectiveness at dust control.

Figure 1 shows an electric powered, hand-held disk grinder (G10SM2, Hitachi Koki Co., Ltd; Japan) with an LEV system that extracts dust by suction close to its point of generation. During the study, the grinder was equipped with a $10 \mathrm{~cm}$ (\#34) abrasive grinding wheel. The LEV system consisted of a suction hood that doubles as a grinding wheel shroud, a flexible corrugated hose $(\phi 25 \mathrm{~mm} \times$ $5 \mathrm{~m}$ ), a dust collector (R30Y3, Hitachi Koki Co., Ltd) that provided an exhaust airflow of $1.51 \mathrm{~m}^{3} / \mathrm{min}$ and a straight exhaust duct $(\phi 41 \mathrm{~mm} \times 84.5 \mathrm{~cm})$. Dust-laden air was conveyed from the tool to the collector through the hose and then exhausted through the duct. The exhaust airflow rate of the collector was calculated as the product of the exhaust duct's cross-sectional area and 0.9 times the air velocity at the exhaust duct's center line ${ }^{2)}$. The take-off of the suction hood was $34 \mathrm{~mm}$ in diameter and was located on the right side of the tool as shown in Fig. 1.

The effectiveness of the LEV for dust control was assessed by determining the respirable dust concentration around the grinding wheel during metal surface grinding with and without the use of the LEV. This strategy was selected because the most pertinent factor in a LEV's performance is the measurement of worker's exposure to metal dust. In the experiments, a $10 \mathrm{~cm} \times 1.5 \mathrm{~cm}$ welding bead produced by $\mathrm{CO}_{2}$ arc welding of solid wire (JIS 


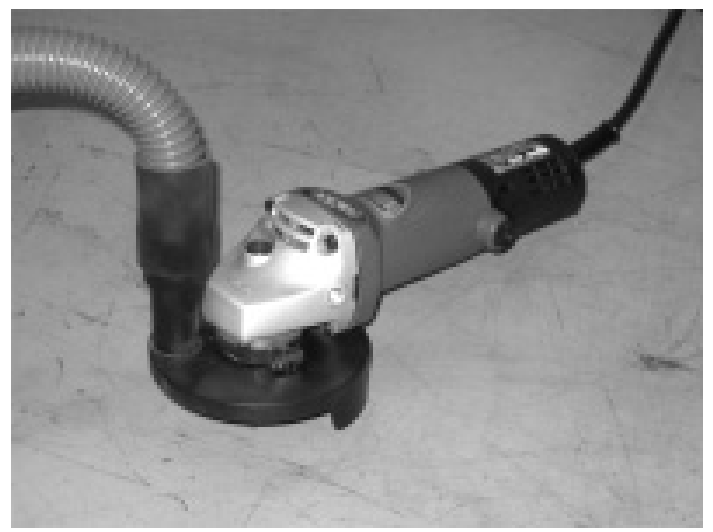

Fig. 1. Hand-held disk grinder equipped with the LEV system.

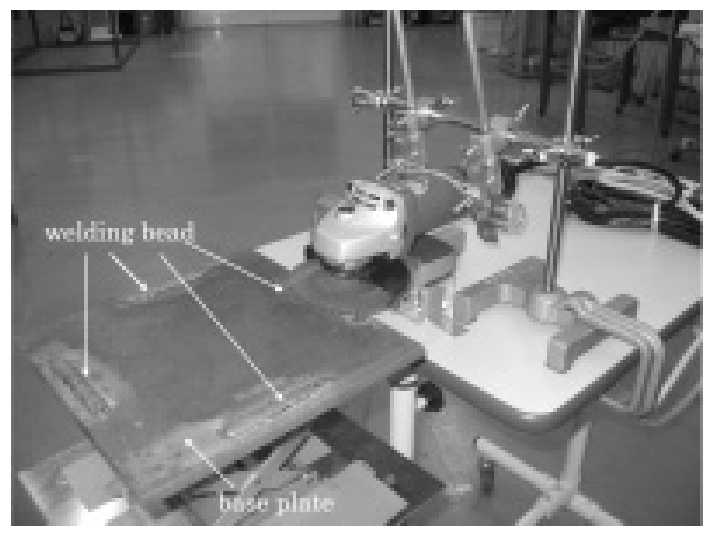

Fig. 2. Ground metal and disk grinder used in this experiment.

The LEV system was removed from the grinder for photographing.

$\mathrm{Z} 3312, \phi 1.2 \mathrm{~mm}$ ) on a base plate was used as the metal to be ground (Figure 2). In each trial, the welding bead was ground for $3 \mathrm{~min}$ with $750 \mathrm{gw}$ loading in a $50 \mathrm{~cm} \times$ $55 \mathrm{~cm} \times 60 \mathrm{~cm}$ PVC chamber which eliminated the effect of draft and trapped all generated grinding dust. The grinding dust was dispersed by the grinding wheel wind and immediately spread homogeneously in the chamber. The respirable grinding dust concentration was measured by a portable light scattering digital dust monitor (DUST MATE model LD-1 $\mathrm{H}_{2}$, SIBATA Scientific Technology Ltd; Japan) which was calibrated by an inertial impact dust sampler (Roken-type low volume air sampler NWPS254, SIBATA Scientific Technology Ltd ). The calibration factor of the dust monitor was $4.45 \times 10^{-3}$ $\mathrm{mg} / \mathrm{m}^{3} / \mathrm{cpm}\left(\mathrm{n}=5\right.$, S.D. $\left.=0.95 \times 10^{-3}\right)$. Since sampling periods of a short duration are commonly used in engineering control and exposure assessment studies $^{3,4)}$, air sampling was carried out only during actual grinding time (3 min) in the PVC chamber. In order to protect the air

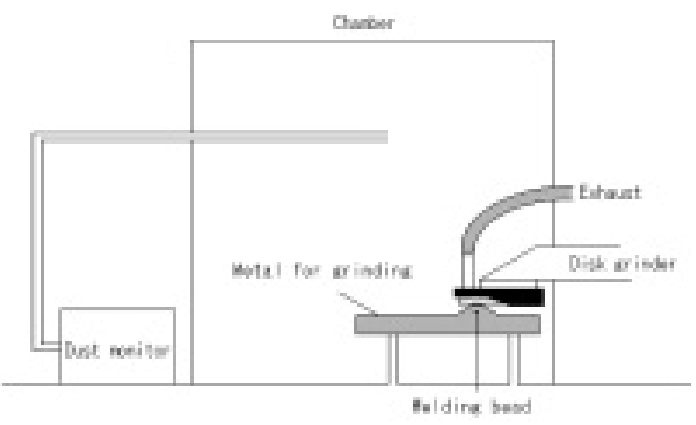

Fig. 3. Schematic diagram of the experiment.

Table 1. Grinding dust concentration during grinding with the LEV system on and off

\begin{tabular}{cc}
\hline LEV system & Dust conc. $\left[\mathrm{mg} / \mathrm{m}^{3}\right]^{*}$ \\
\hline OFF & $7.73 \pm 1.70$ \\
ON & $4.87 \pm 1.01$ \\
\hline
\end{tabular}

*: Values are arithmetic mean \pm S.D. $(n=10)$.

sampler from the grinding spatters, a distance of $40 \mathrm{~cm}$ was maintained between the grinding wheel and the sampling point (Fig. 3). Following the completion of each trial, the inside of the chamber was cleaned using a filter vacuum $\left(1.4 \mathrm{~m}^{3} / \mathrm{min}\right)$ to minimize contamination between trials.

Table 1 shows the LEV's effectiveness in dust control. The average respirable grinding dust concentration decreased from $7.73 \mathrm{mg} / \mathrm{m}^{3}$ with the LEV off to 4.87 $\mathrm{mg} / \mathrm{m}^{3}$ with the LEV on, a mean dust generation reduction of about $37 \%$. From the dust concentration and the chamber volume, the generation rate of respirable grinding dust was assumed to be about $1.3 \mathrm{mg} / \mathrm{min}$ when a 10 $\mathrm{cm}$ disk grinder is applied to a welding metal.

Although some reduction in dust concentration was achieved, the effectiveness of the tool-mounted LEV on the hand-held disk grinder was not sufficient and worker exposure could not be prevented completely by the LEV alone. Unlike a disk sander which is used to grind concrete surfaces, it is structurally impossible to enclose the entire grinding wheel by a shroud in the case of a disk grinder. Therefore, some grinding dust escaped from the clearance between the shroud and the ground metal. However, it is still thought reasonable to recommend the LEV as a grinding dust control measure because no other effective measures currently exist, except the costly pushpull ventilation system. Despite incomplete control, the LEV would reduce the risk of workers developing pneumoconiosis, allow workers to use a lower level of respiratory protection, reduce exposure to nearby workers, and reduce clean-up associated with dust exposure at low cost.

The chance of lowering exposure would be better if 
more than one measure to control dust exposures were combined. It would be advisable to use another dust control measure in conjunction with the LEV, such as a general ventilation system.

\section{References}

1) Ojima J (2007) Metal dust exposure and control in handheld grinding operation. San Ei Shi 49, 9-11 (in Japanese).
2) Heitbrink WA, Cooper TC, Edmonds MA (1994) Evaluation of ventilated sanders in the autobody repair industry. Am Ind Hyg Assoc J 55, 756-9.

3) Croteau GA, Flanagan ME, Camp JE, Seixas NS (2004) The efficiency of local exhaust ventilation for controlling dust exposures during concrete surface grinding. Ann Occup Hyg 48, 509-18.

4) Ojima J (2006) Performance of a fume-exhaust gun system in $\mathrm{CO}_{2}$ arc welding. J Occup Health 48, 207-9. 